\title{
CONTRIBUIÇÃO A METALOGÊNESE DO ESTANHO EM MEIO SUPÉRGENO - A JAZIDA DE SERRA DA ONÇA B EM RONDÔNIA
}

\author{
SÔNIA M.B. OLIVEIRA* \& JÚLIO C.P.VALENTE**
}

\begin{abstract}
CONTRIBUTION TO TIN METALOGENESIS IN SUPERGENE ENVIRONMENT - THE SERRA DA ONÇA B DEPOSIT IN RONDÔNIA. In the Serra da Onça B, State of Rondônia, Brazil, a supergene tin deposit has been derived by weathering of the Santa Barbara granite and greisenized gneissic country rock. Cassiterite is concentrated in the upper two horizons of a lateritic weathering profile comprised, from bottom to top, by a saprolitic level, a stone line of ferruginous nodules and loose-clay level. On the basis of geochemical and micromorphological evidence, this article suports the hypotesis of an autochthonous origin for the Serra da Onça B stone line lateritic profiles. Accordingly, they are thought to have resulted from secondary in situ transformation of an older cassiterite-rich ferricrete formed under dryer climatic conditions that supposedly prevailed in the region during the early Tertiary. Due to the northward drift of South America since then, the climate has become more homid, leading to the dismantling of the ferricrete. The remnants of this former pedological system are the ferruginous nodules that form the stone line. This hypothesis opposes the currente view that considers these profiles as the result of colluvial processes related to Quaternary climatic fluctuations.
\end{abstract}

Keywords: Lateritic stone line, secondary tin mineralization, ferricrete.

\begin{abstract}
RESUMO Na jazida de estanho de Serra da Onça B, no Estado de Rondônia, as concentrações de cassiterita situam-se em perfis de alteração intempérica portadores de um horizonte com stone Line laterítica. Esses perfis encontram-se sobre o Granito Santa Bárbara e os gnaisses greisenizados encaixantes, fontes primárias de mineralização. Baseado principalmente em argumentos geoquímicos e micromofológicos, este trabalho sustenta a hipótese de uma origem autóctone para os perfis de Serra da Onça B. Eles seriam derivados de uma couraça ferruginosa enriquecida em cassiterita que teria se formado sob condições climáticas mais secas, prevalecentes na região até o Eoceno. Com o deslocamento do continente sul-americano em direção ao norte durante o Terciário, o clima em Rondônia foi se tornando cada vez mais úmido, o que resultou na degradação m situ da couraça, que deixou como resíduo o horizonte a stone Line laterítica. Esta hipótese contraria a interpretação geralmente admitida para esses perfis, que os considera produtos do coluvionamento ocorrido por ocasião das flutuações climáticas quaternárias.
\end{abstract}

Palavras-chave: Stone Line laterítica, mineralização secundária de estanho, couraça.

INTRODUÇÃO A Província Estanífera de Rondônia compreende dezenas de depósitos de cassiterita relacionados principalmente aos chamados "Granitos Rondonianos". Há toda uma variedade de tipos, desde os de origem primária, relacionados direta ou indiretamente aos granitos, até os aluvionares, passando por depósitos eluvionares e coluvionares.

No distrito de Santa Bárbara, situado aproximadamente a $150 \mathrm{~km}$ a sudeste de Porto Velho (Fig. 1), há várias jazidas, entre as quais a de Serra da Onça B, objeto deste trabalho. Nessa jazida, as concentrações de cassisterita encontram-se em perfis de alteração com stone Line laterítica, desenvolvidos sobre o Granito Santa Bárbara e os gnaisses encaixantes.

Este trabalho tem como objetivo investigar os processos que levaram à elaboração do perfil ferralítico e a consequente concentração de cassiterita. De início, será feita a caracterização estrutural, mineralógica e química dos horizontes componentes do perfil de alteração, levando em conta sua variabilidade vertical e lateral. Em seguida, serão traçadas comparações com perfis similares descritos na África e no Brasil. Finalmente, será proposta uma hipótese explicativa para a génese e evolução dessas formações.

\section{CONTEXTO GEOLÓGICO E MORFOCLIMÁTICO}

Regional A Província Estanífera de Rondônia está contida na Província Estrutural de Tapajós, que constitui a parte meridional do Cráton Amazônico (Almeida et al. 1981). São observados granitos anorogênicos de diferentes idades, intrusivos em rochas arqueanas do Complexo Xingu (Fig. 1). Esses granitos são classificados em várias suítes, das quais destacam-se os chamados "Granitos Rondonianos" (Lean et al. 1978), considerados como sendo corpos de natureza subvulcânica, com forma aproximadamente circular e idades entre 1.100 e 930 milhões de anos.

As mineralizações primárias de estanho estão associadas a intensos processos de alteração metassomática que afetaram os granitos e as rochas do embasamento. São dominantes os depósitos de caráter essencialmente de substituição metassomática pós-magmática. A cassiterita acha-se concentrada nas bordas dos corpos graníticos e nas encaixantes próximas, proncipalmente sob forma disseminada, em veios e filões de quartzo ou como stockwork associado a corpos greisenizados (Bettencourt \& Dall'Agnol 1987).

A região dos granitos estaníferos situa-se na bacia do Rio Madeira, numa área pertencente à unidade morfoclimática designada de "Planalto rebaixado da Amazônica ocidental", onde as formas de dissecação mais comuns são interflúvios tabulares. O relevo compreende elevações de topos aplainados, separados por vales de fundo geralmente plano, com índice de dissecação muito fraco (Leal et al. 1978).

O clima atual é quente e úmido, caracterizado por uma precipitação média anual em torno de $2.250 \mathrm{~mm}$ e uma temperatura média anual de $24^{\circ} \mathrm{C}$. Os meses de junho, julho e agosto são relativamente mais secos, com precipitação média não ultrapassando $100 \mathrm{~m}$.

Local O depósito de Serra da Onça B está associado ao Granito Santa Bárbara, localizado na bacia do Rio Jamari, afluente do Rio Madeira. A mineralização primária é repre-

\footnotetext{
* Instituto de Geociências, Universidade de São Paulo, Caixa Postal 20899, CEP 01498-970, São Paulo, SP, Brasil

** Rua Coronel Tamarindo, 83, CEP 02100-000, São Gonçalo, Rio de Janeiro, RJ
} 


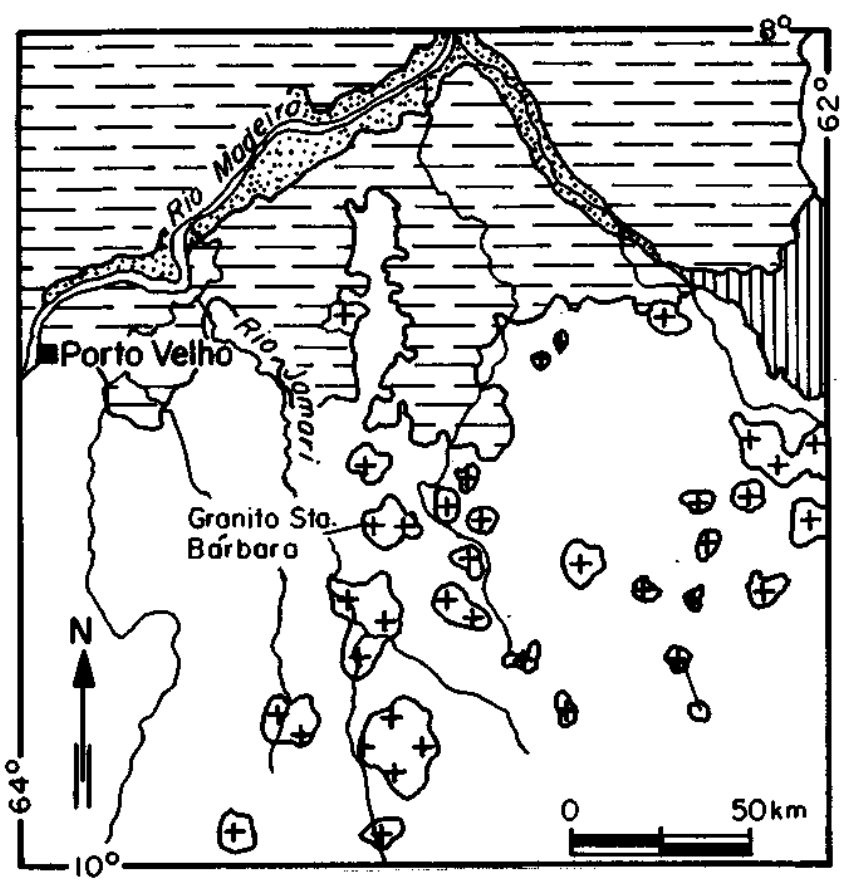

\section{LEGENDA}

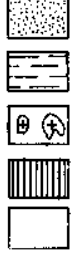

Aluviões (Quaternário)

Arenitos e Siltitos (Quaternário)

Granitos (Proterozóico Superior)

Formação Prainha (Proterozóico Médio)

Complexo Xingu (Arqueano)

Figura 1 - Mapa geológico regional (Schobbenhaus et al. 1981)

Figure 1 - Regional geologic map (Schobbenhaus et al. 1981)

sentada por cassiterita em veios de quartzo que cortam as bordas do granito e suas encaixantes; os gnaisses greisenizados. A direção desses veios é N30-40E, com mergulhos de 25 a 50SE, seguindo o mesmo controle estrutural de mineralização do próprio granito (Carvalho 1988).

A jazida, já parcialmente explotada, compreende as formações de cobertura sobre a rocha alterada derivada do gnaisse greisenizado. Dispõe-se no flanco noroeste da Serra da Onça, contida numa área de aproximadamente $3,8 \mathrm{~km}$ de extensão, com largura variando de 0,3 a 1,2 km (Fig. 2). As altitudes estão entre $130 \mathrm{~m}$ - nos topos - e $90 \mathrm{~m}$, no fundo do vale.

AS FORMAÇÕES DE COBERTURA NA JAZIDA DE SERRA DA ONÇA B Aspectos gerais Informações provenientes do exame de mais de uma centena de resultados de furos de sondagem e percussão e de cortes abertos pelos trabalhos de lavra permitiram evidenciar as principais feições na escala do depósito (Valente 1991).

- O perfil de alteração tem espessura de mais de $40 \mathrm{~m}$, pois a rocha fresca não aparece na base dos furos de até essa profundidade.

- O perfil de alteração, de natureza ferralítica, apresenta-se diferenciado em três horizontes: um horizonte saprolítico (H3) na base, um horizonte portador de nódulos lateríticos (H2) na porção intermediária e um horizonte móvel (H1) no topo. É nos dois últimos horizontes que se dá o maior enriquecimento em cassiterita.

- As espessuras dos perfis de alteração aumentam para NW, em direção às porções inferiores das encostas. $\mathrm{O}$ horizonte nodular $(\mathrm{H} 2)$ varia geralmente de 0 a $6 \mathrm{~m}$ de espessura e o horizonte móvel do topo $(\mathrm{H} 1)$ de 0 a $7 \mathrm{~m}$. A espessura do horizonte $\mathrm{H} 3$ é desconhecida.

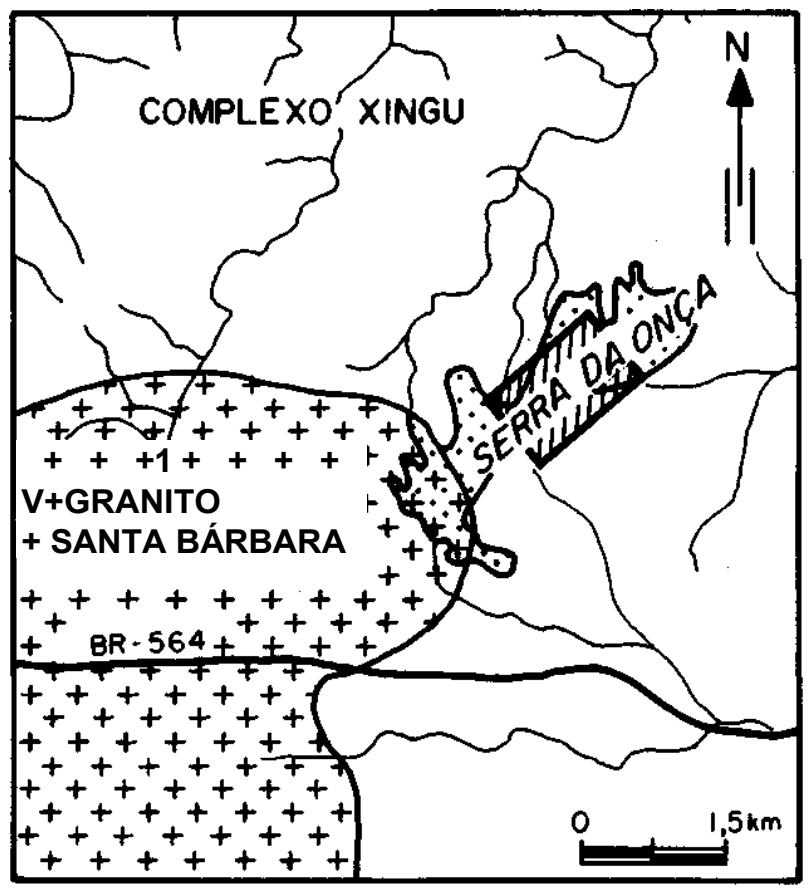

Figura 2 - Mapa geológico do Granito Santa Bárbara mostrando o depósito de Serra da Onça B (Bettencourt \& Dall'Agnol 1987)

Figure 2 - Geologic map of the Santa Bárbara Granite, showing the Serra da Onça B deposit (Bettencourt \& Dall'Agnol 1987)

- O horizonte nodular é descontínuo nos topos, torna-se contínuo e de espessura crescente ao longo das encostas, e próximo aos talvegues os nódulos aprecem soldados em couraça (Fig. 3). Assim, na escala do interflúvio, o encouraçamento aparece nos trachos inferiores das encostas.

- Os mapas de isoteores de $\mathrm{Sn}$ em H1 e H2, elaborados durante a fase de prospecção de jazida, para o setor representado por um retângulo na figura 2 , mostram anomalias superponíveis orientadas na direção NE (Fig. 4).

- O coeficiente de correlação Pearson entre os teores de Sn em H1 e H2 no setor acima citado, calculado para 143 amostras, é de $+0,42$, o que é significativo ao nível de $99 \%$.

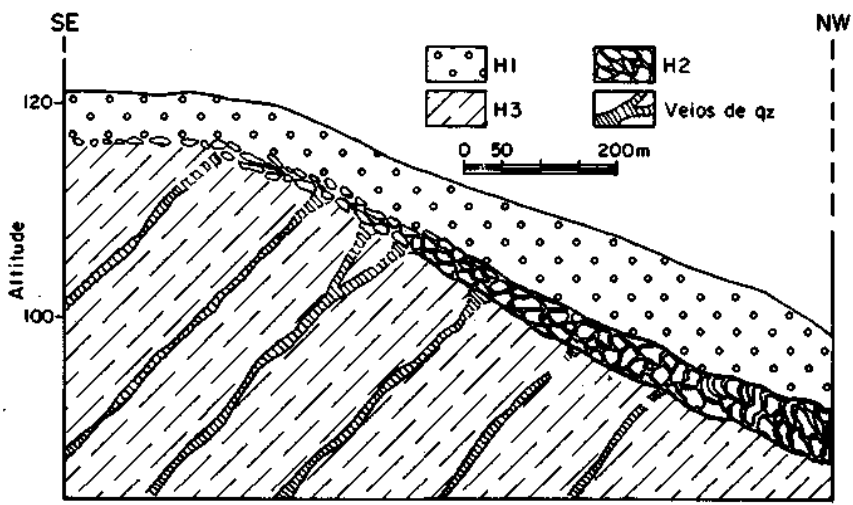

Figura 3 - Seção transversal esquemática para Serra da Onça $\mathrm{B} \cdot \mathrm{H}_{1}, \mathrm{H}_{2}$, e $\mathrm{H}_{3}$ - ver texto para detalhes Figure 3 - Schematic cross section in Serra da Onça B $\bullet \mathrm{H}_{1} \mathrm{H}_{2}$, and $\mathrm{H}_{3}$ - see text for details 
- De modo geral, em zonas mineralizadas, os teores de Sn em Hl variam de 50 a $500 \mathrm{~g} / \mathrm{m}^{3}$ e em H2 500 a $5.000 \mathrm{~g} / \mathrm{m}^{3}$, isto é, o teor de $\mathrm{Sn}$ em H2 é de uma ordem de grandeza maior que em $\mathrm{Hl}$; fora delas, os teores de $\mathrm{Sn}$ tanto em $\mathrm{Hl}$ quanto $\mathrm{em} \mathrm{H} 2$ variam entre $10 \mathrm{e} 100 \mathrm{~g} / \mathrm{m}^{3}$.
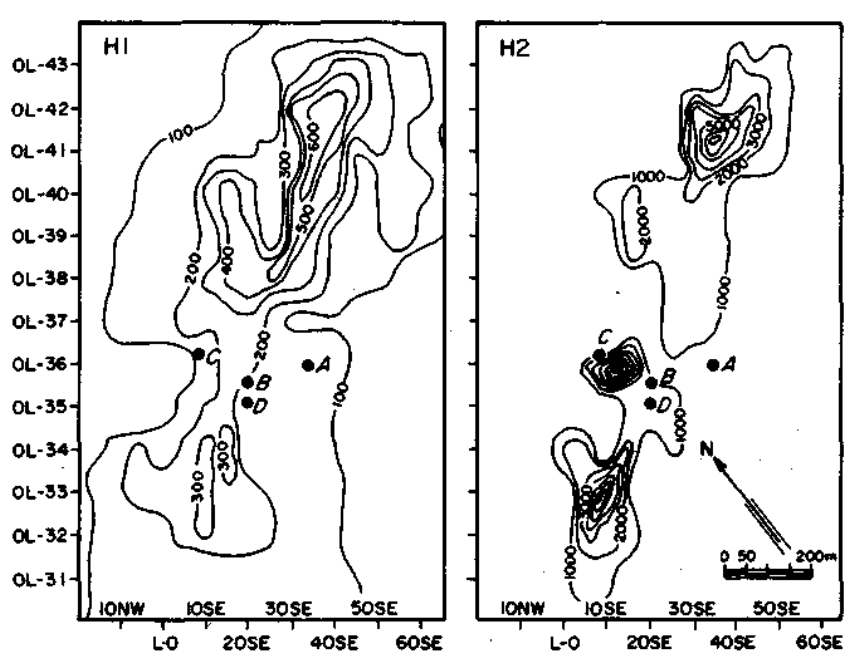

Figura 4-Mapas de isoteores de Sn $\left(\mathrm{g} / \mathrm{m}^{3}\right)$ em H1 e H2 Figure 4 - Map of Sn-contour $\left(\mathrm{g} / \mathrm{m}^{3}\right)$ in $\mathrm{Hl}$ and $\mathrm{H} 2$

- Em Hl, a amplitude da variação do teor de Sn da zona nãomineralizada para a zona mineralizada é menor que em $\mathrm{H} 2$. Fora das zonas mineralizadas, o teor de $\mathrm{Sn}$ em $\mathrm{Hl}$ é um pouco maior que em H2. As anomalias são, portanto, mais espalhadas em $\mathrm{Hl}$ que em $\mathrm{H} 2$.

Estudo de detalhe OS PERFIS ESTUDADOS Para estudos de maior detalhe, foram selecionados quatro perfis de alteração (A, B, C e D), na zona mineralizada, em diferentes altitudes (Fig. 4). Esses perfis estão expostos na parede de uma grande cava, de onde o minério foi lavrado. A escavação, que visava retirar o material correspondente a $\mathrm{Hl}$ e H2, parou logo que atingiu H3, razão pela qual este horizonte só vai aparecer nos perfis representado pela sua porção superior. Apenas muito localmente, a escavação é mais funda e expõe a parte inferior de H3. O chão da cava é, portanto, cortado em H3, onde aparecem nitidamente os veios de quartzo orientados a NE.

O perfil A, situado a $114 \mathrm{~m}$ de altitude, apresenta $\mathrm{H} 1$ de 1 $\mathrm{m}$ de espessura, $\mathrm{H} 2$ e $\mathrm{H} 3$ de $0,7 \mathrm{~m}$. Em B, com cota $1,30 \mathrm{~m}$ abaixo de A, Hl é espesso de $1 \mathrm{~m}, \mathrm{H} 2$ de $0,7 \mathrm{~m}$ e H3 está exposto por $8 \mathrm{~m}$. Em C, a $10 \mathrm{~m}$ abaixo de A, Hl mede $2 \mathrm{~m}$ de espessura, $\mathrm{H} 2,1 \mathrm{~m}$ e $\mathrm{H} 3$ apenas $0,30 \mathrm{~m}$. O perfil $\mathrm{D}$ fica em cota intermediária entre $\mathrm{B}$ e $\mathrm{C} ; \mathrm{Hl}$ tem $1 \mathrm{~m}$ de espessura, assim como $\mathrm{H} 2$, e H3 está escavado por $4 \mathrm{~m}$.

\section{AMOSTRAGEM E METODOLOGIA DE TRATAMENTO} $D A S$ AMOSTRAS Foram selecionadas amostras representativas dos horizontes de alteração presentes nos perfis A, $\mathrm{B}$ e C. De alguns horizonte foi retirada apenas uma amostra e, de outros, duas, que receberam a denominação de (a) e (b), estando a primeira sempre em posição superior no perfil. Essas amostras foram laminadas para microscopia óptica e submetidas à análise granulométrica; em cada fração foi efetuada análise por difração de raios $\mathrm{X}$ e dosagem química de Sn. Foram determinados os minerais pesados nas várias frações granulométricas dos concentrados de bateia representativos dos vários horizontes. O perfil $\mathrm{D}$ foi amostrado metro a metro para análise química multielementar, que também foi efetuada sobre amostras representativas do 3 horizontes do perfil C.

CARACTERIZAÇÃO MINERALÓGICA E MICROESTRUTURAL DOS TRES HORIZONTES DE ALTE$R A C ̧ \tilde{A} O$ A distribuição granulométrica referente aos três horizontes componentes dos perfis A, B e C está representada nas figuras 5,6 e 7. Os resultados da difração de raios $\mathrm{X}$ para as várias fracões granulométricas referentes ao perfil B estão representados na tabela 1. Esses dados, e os obtidos através do estudo micromorfológico de seções delgadas provenientes dos três horizontes presentes nos perfis, permitiram elaborar a caracterização que se segue.

O horizonte saprolítico da base (H3) Nesse horizonte podem-se distinguir dois níveis:

- um nível mais profundo, de espessura desconhecida, onde a textura de rocha é reconhecível. Trata-se de uma isalterita derivada de rocha gnáissica, em que é possível discernir níveis rosados intercalados com níveis esbranquiçados que assinalam a gnaissificação, sendo todo o material recortado por veios de quartzo. Ao microscópio, os feldspatos aparecem totalmente pseudomorfizados em caulinita, e os grãos de quartzo, apesar de fraturados, mantêm-se sem deslocamento; os minerais ferromagnesianos acham-se transformados em goethita. Em direção ao topo, as estruturas da rocha vão desaparecendo gradativamente.

- um nível superior, de espessura em torno de $7 \mathrm{~m}$, em que a textura da rocha já não é reconhecível (aloterita), embora a estrutura geral seja conservada, o que é evidenciado pela permanência dos veios de quartzo nas posições que originalmente mantinham na isalterita. Macroscopicamente, apre-


Figura 5 - Distribuição granulométrica e teores de Sn $(\%$ em peso) para os horizontes de alteração do perfil $A$ Figure 5 - Granulomelric distribution and Sn contents (weight \%) for the weathering horizons of the A profile 

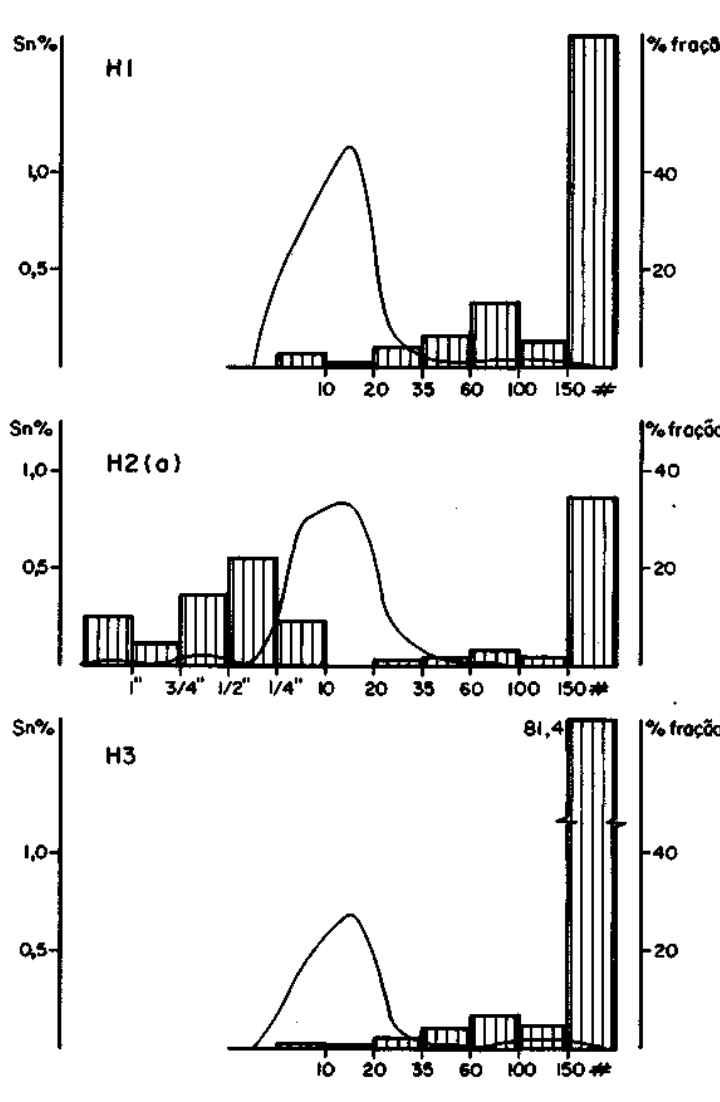

Figura 6 - Distribuição granulométrica e teores de Sn $(\%$ em peso) para os horizontes de alteração do perfil $B$ Figure 6 - Granulometric distribution and Sn contents (weight \%) for the weathering horizons of the $\mathrm{B}$ profile

senta-se como um material homogêneo, areno-argiloso, de coloração vermelho-rosada. A transição para o horizonte nodular que o recobre $(\mathrm{H} 2)$ faz-se através do aparecimento de manchas ferruginosas endurecidas, que vão dando ao material uma coloração vermelha mais carregada, e dos veios de quartzo que se desagregam e se misturam ao resto do material. Ao microscópio, apresenta um fundo matricial composto por um plasma marrom-avermelhado de caulinita, goethita e quartzo, que corresponde à fração granulométrica (150\# ou $<0,105 \mathrm{~mm}$ e representa 82 a $84 \%$ do total, e um esqueleto (fração entre 20 e $150 \#$ ou 0,84 e $0,105 \mathrm{~mm}$, representando cerca de $15 \%$ do total), formado por grãos de quartzo submilimétricos muito fraturados, alguns raros grãos de mica ferruginizada, e por poros de forma irregular. Ocorre ainda uma pequena quantidade, geralmente menor que $1 \%$, de nódulos milimétricos formados principalmente por goethita e caulinita, com um pouco de quartzo (fração $>$ $10 \#$ ou $>1,68 \mathrm{~mm}$ ). Há sinais de um início de pedoturbação, que se evidencia por uma certa dispersão do esqueleto e orientação do plasma.

$O$ horizonte nodular (H2) Esse horizonte, descrito como stone Line laterítica, compõe-se de nódulos ferruginosos grossos, envolvidos por um material areno-argiloso avermelhado. As curvas granulométricas de $\mathrm{H} 2$ (Fig. 5, 6 e 7) mostram nitidamente a descontinuidade que separa os nódulos de matriz, através do corte correspondente à granulação entre 10 e $20 \#(1,68$ e $0,84 \mathrm{~mm})$. A transição para o horizonte do topo $(\mathrm{H} 1)$ dá-se pelo quase total desapareci-
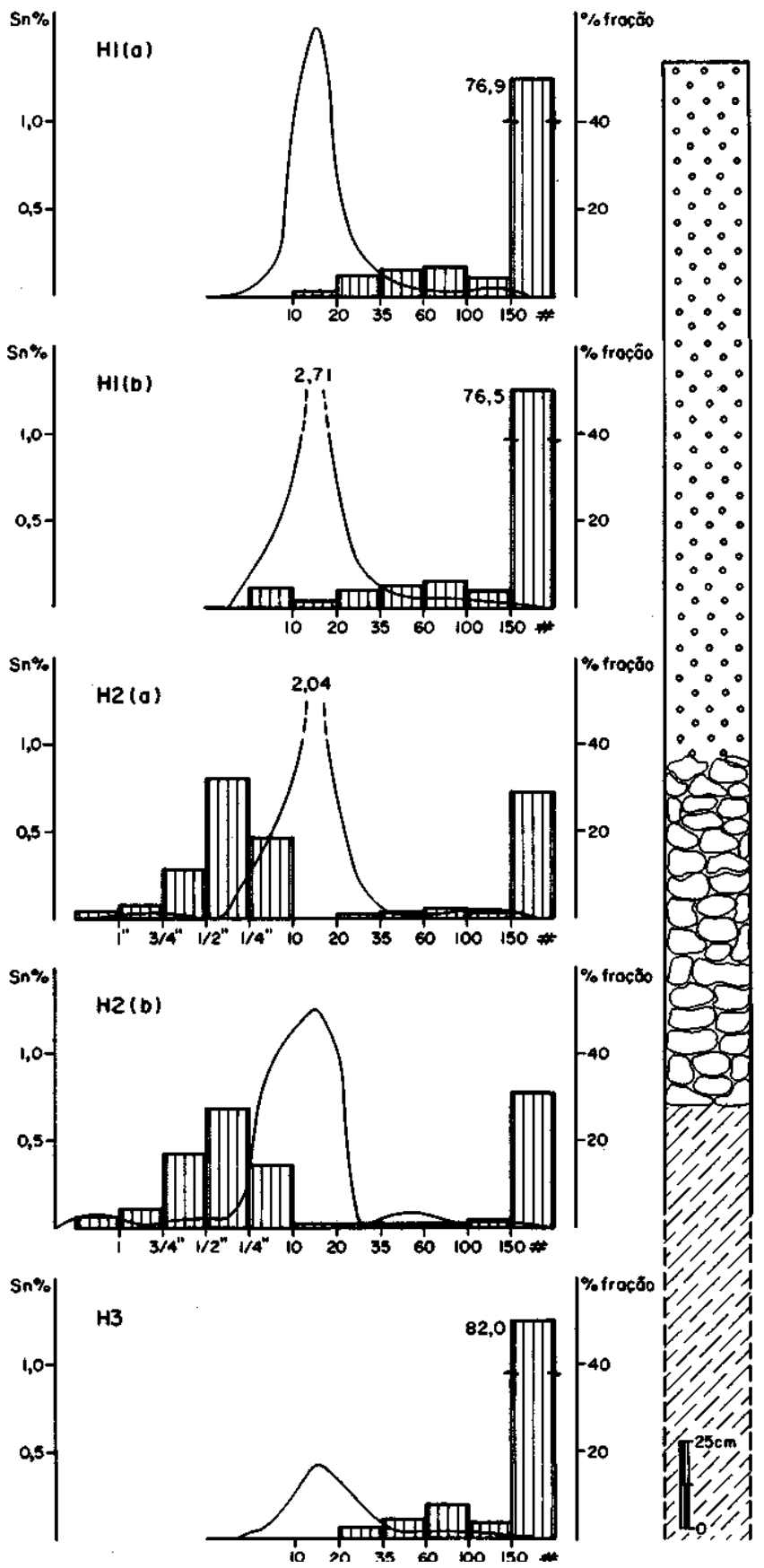

Figura 7 - Distribuição granulométrica e teores de Sn $(\%$ em peso) para os horizontes de alteração do perfil $C$ Figure 7 - Granulometric distribution and Sn contents (weight \%) for the weathering horizons of the $\mathrm{C}$ profile

mento dos nódulos. O contato $\mathrm{H} 2-\mathrm{H} 1$ tende a acompanhar aproximadamente a topografia.

$\mathrm{O}$ fundo matricial internodular é semelhante ao de H3, apresentando um plasma avermelhado constituído por caulinita, goethita e quartzo (fração $<150 \#$ ou $<0,105 \mathrm{~mm}$ ), e um esqueleto principamente quartzoso (fração entre $20 \mathrm{e}$ $150 \#$ ou 0,84 e $0,105 \mathrm{~mm})$. Os nódulos, que constituem 49 a $65 \%$ do horizonte (fração $>10 \#$ ou $>1,68 \mathrm{~mm}$ ), possuem formas irregulares e medem até 3 ou $4 \mathrm{~cm}$ de diâmetro. Quando menores, são mais avermelhados e possuem córtex marrom espesso e, quando maiores, são amarelados, geralmente desprovidos de córtex; no caso de o possuírem, este é 
Tabela 1 - Avaliação semi-quantitativa dos minerais presentes em cada fração granulométrica para as amostras do perfil $B .(x)=$ traços; $x=$ pouco abundante; $x x=$ abundante $; x x x=$ muito abundante

Table 1 - Mineralogical semi-quantitative evaluation in granulometric fractions for profile $\mathrm{B}$ samples. $(\mathrm{x})=$ traces; $\mathrm{x}=$ not very abundant; $\mathrm{xx}=$ abundant; $\mathbf{x x x}=$ very abundant

\begin{tabular}{|c|c|c|c|c|}
\hline H1 & Quartzo & Goethita & Caulinita & Mica \\
\hline$>10 \#$ & $x x$ & $x x x$ & $\mathbf{x x}$ & \\
\hline$>20 \#$ & $\mathbf{x x x}$ & $\overline{x x}$ & $x x$ & $x$ \\
\hline$>35 \#$ & $x x x$ & & $\mathbf{x}$ & $x x$ \\
\hline$>60$ \# & $\mathrm{xxx}$ & & $\mathrm{x}$ & $x x$ \\
\hline$>100 \#$ & $x x x$ & & $x$ & $x x$ \\
\hline$>150 \#$ & $\mathbf{x x x}$ & & & $x x$ \\
\hline$<150 \#$ & $x x$ & $x x$ & $x x x$ & \\
\hline H2(a) & Quartzo & Goethita & Caulinita & Mica \\
\hline$>1^{n}$ & $(x)$ & $x x x$ & $x x$ & \\
\hline$>3 / 4^{\prime r}$ & $(x)$ & $\mathbf{x x x}$ & $\mathrm{xx}$ & \\
\hline$>1 / 2^{\prime \prime}$ & $(x)$ & $\mathbf{x x x}$ & $x x$ & \\
\hline$>1 / 4^{\prime \prime}$ & $(x)$ & $\operatorname{xxx}$ & $\pi x$ & \\
\hline$>10 \#$ & $x x$ & $\mathbf{x x x}$ & $x x$ & \\
\hline$>20 \#$ & $\mathrm{xxx}$ & $\mathbf{x x}$ & $x x$ & \\
\hline$>35 \#$ & $\mathbf{x x x}$ & & (x) & $\mathbf{x x}$ \\
\hline$>60 \#$ & $x x x$ & & & $x x$ \\
\hline$>100 \#$ & $\mathbf{x x x}$ & & & $\mathbf{x x}$ \\
\hline$>150 \#$ & $x x x$ & & & $\mathbf{x x}$ \\
\hline$<150 \#$ & $x x$ & $\mathrm{xx}$ & $x x x$ & \\
\hline $\mathbf{H 3}$ & Quartzo & Goethita & Caulinita & Mica \\
\hline$>10 \#$ & $x$ & $x x x$ & $\mathrm{xxx}$ & \\
\hline$>20 \#$ & $x x x$ & $x x$ & $\mathbf{x x}$ & \\
\hline$>35 \#$ & $x x x$ & $x$ & $x$ & $x$ \\
\hline$>60 \#$ & $\mathrm{xxx}$ & & $x$ & $x$ \\
\hline$>100 \#$ & $\mathrm{xxx}$ & & $x$ & $x$ \\
\hline$>150 \#$ & $x \times x$ & & $x$ & $x$ \\
\hline$<150 \#$ & $(x)$ & $x x$ & $x x x$ & \\
\hline
\end{tabular}

vermelho, de espessura submilimétrica e descontínuo. De modo geral, os nódulos são compostos essencialmente por goethita e caulinita. Ao microscópio, mostram um plasma argilo-ferruginoso poroso, com raros grãos de cassiterita e quartzo; este mineral apresenta bordas corroídas, parecendo boiar no plasma intranodular.

O horizonte móvel do tipo (HI) É um material arenoargiloso marrom-amarelado, macroscopicamente homogéneo, contendo 1 a $5 \%$ de pequenos nódulos lateríticos (fração $>10 \#$ ou $>1,68 \mathrm{~mm}$ ), mais concentrados na parte basal do horizonte. $\mathrm{O}$ fundo matricial compreende um plasma amarelo argiloferruginoso, que corresponde a 68 a $77 \%$ do total (fração $<150 \#$ ou $<0,0105 \mathrm{~mm}$ ), um esqueleto representado principalmente por quartzo, em grãos que vão desde frações de $\mathrm{mm}$ a cerca de $1 \mathrm{~mm}$ de diâmetro (fração entre 20 e $150 \#$ ou 0,84 e $1,105 \mathrm{~mm}$ ), e poros irregulares, mais abundantes em direção à superfície. Os nódulos, embora bem menores, são semelhantes aos encontrados em $\mathrm{H} 2$.

DISTRIBUIÇAO DO SN NAS FRACUÕES GRANULOMETRICAS Nas figuras 5,6 e 7, sobrepostos à distribuição granulométrica, são indicados os teores de $\mathrm{Sn}$ em porcentagem em peso. Em H3, os teores máximos situam-se entre 0,5 e $0,7 \% \mathrm{Sn}$, em $\mathrm{H} 2$ entre 1,3 e $2,0 \%$ e em $\mathrm{H} 1$ entre 1,0 e $2,7 \%$

Em todos os horizontes é nos intervalos entre 1/4"e 10\# $(6,4 \mathrm{~mm}$ a $1,68 \mathrm{~mm})$ ou $>10 \#(>1,68 \mathrm{~mm})$, e principalmente entre 10 e $20 \#(1,68$ a $0,84 \mathrm{~mm})$, que se encontram os teores mais altos de Sn. No entanto, esse último intervalo granulométrico é praticamente desprovido de material em todos os horizontes, constituindo justamente o intervalo de corte entre o fundo matricial e os nódulos lateríticos. Desse modo, a fração granulométrica mais rica em $\mathrm{Sn}$ é a fração $>1,68$ mm. Outra feição comum a todos os horizonte são os teores extremamente baixos, da ordem de $0,01 \%$ de Sn, para a fração $<150 \#(<0,105 \mathrm{~mm})$.

Em resumo, pode-se dizer que a maior parte da cassiterita é de dimensão milimétrica. No horizonte nodular, as frações superiores a 1/4"(6,4 mm), que correspondem aos nódulos maiores, são pobres em Sn, refletindo a quase completa ausência de cassiterita no seu interior. Esse mineral, juntamente com o quartzo, compõe, como já foi visto no item anterior, o esqueleto do fundo matricial internodular.

COMPORTAMENTO DOS MINERAIS PESADOS NO PERFIL A fração pesada corresponde aos vários horizontes do perfil de alteração compreende os mesmos minerais: cassiterita, zircão, topázio, ilmenita e magnetita. Quartzo e concreções lateríticas acompanham a fração pesada. Os teores de cassiterita são máximos no horizonte H2 e mínimos em $\mathrm{H} 3$

De modo geral, essa fração é composta por uma parte não-magnética, que representa aproximadamente $1 / 4$ do peso total, e por uma parte magnética que corresponde aos $3 / 4$ restantes. Entre os não-magnéticos, estão principalmente a cassiterita, mais abundante na granulação entre 5 e $40 \#$ (4 e $0,40 \mathrm{~mm})$, o zircão, geralmente menor que $100 \#(<0,149$ $\mathrm{mm})$, e o quartzo, de granulação entre 40 e $100 \#(0,40$ e $0,149 \mathrm{~mm}$ ), para a maior parte dos grãos. A parte magnética da fração pesada constitui-se principalmente de nódulos lateríticos (5 a $20 \#$ ou 4 a $0,84 \mathrm{~mm}$ ) e de grãos de magnetita e ilmenita menores que $100 \#(<0,149 \mathrm{~mm})$.

$\mathrm{Na}$ tabela 2, está indicada a distribuição granulométrica da cassiterita no concentrado de bateia para cada um dos horizontes dos perfis A, B e C. Essa distribuição granulométrica não compreende à do material original, representativo de cada horizonte do perfil, porque no processo de geração do concentrado de bateia há perda dos finos. Porém, isso não muda muito o quadro geral, pois, como foi mostrado nas figuras 5,6 e 7, a fração mais fina do material original é muito empobrecida em $\mathrm{Sn}$.

Da análise dos dados ressalta que, nos três horizontes considerados, a maior parte dos grãos de cassiterita é maior que $40 \#(>0,4 \mathrm{~mm})$. Em H3, a cassiterita está dispersa no plasma do fundo matricial, compondo, juntamente com os grãos de quartzo, mas de granulação em média maior que a deles, o esqueleto. Em H2, a cassiterita também está dispersa no plasma, mas apresenta granulação maior (mais de $80 \%$ dos grãos é maior que $10 \#$ ou $1,68 \mathrm{~mm}$ ), da ordem de grandeza dos nódulos menores, sendo, aliás, perfeitamente visível a olho nu nesse horizonte. Em $\mathrm{Hl}$, a cassiterita tende a ser mais fina (mais de $30 \%$ submilimétrica, menor que $20 \%$ ou $0,84 \mathrm{~mm})$, mas ainda é mais grossa que a maior 
parte dos grãos de quartzo que com ela compõem o esqueleto do fundo matricial.

Tabela 2 - Distribuição granulométrica de cassiterita no concentrado de baleia (\%) dos horizontes componentes dos perfis $A, B$ e $C$

Table 2 - Cassiterite granulometric distribution (\%) in the heavy fraction for the three horizons of $\mathrm{A}, \mathrm{B}$ and $\mathrm{C}$ profiles

Perfil A

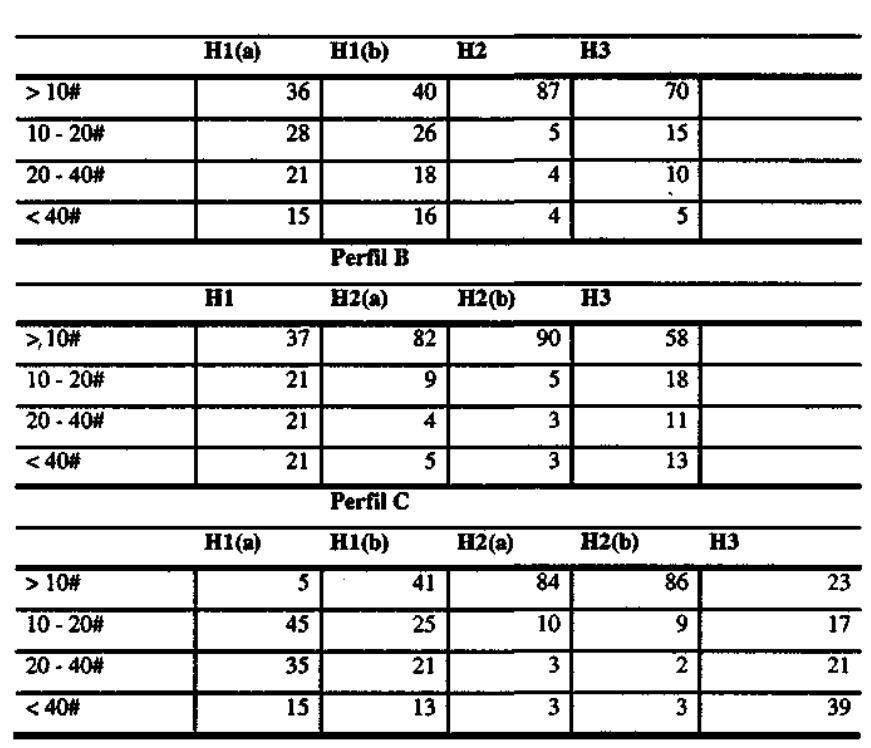

GEOQUÍMICA DO PERFIL DE ALTERAÇAO A tabela 3 mostra os resultados da análise química de A1 e Fe para os perfis $\mathrm{C}$ e $\mathrm{D}$, e as porcentagens aproximadas das principais fases existentes, calculadas a partir desses valores e dos dados difratométricos. No perfil $\mathrm{D}$, as amostras superiores de H3 (2 - $4 \mathrm{~m})$ representam material aloterítico e, as duas inferiores $(4-6 \mathrm{~m})$, material isalterítico. Em ambos os perfis, no horizonte nodular, a quantidade de goethita é máxima, e no horizonte móvel do topo há menos goethita e mais quartzo, comparado com o horizonte saprolítico.

A tabela 4 traz os teores dos traços nos dois perfis analisados. Há um grupo de elementos que se concentram em $\mathrm{H} 2$ : $\mathrm{B}, \mathrm{Ba}, \mathrm{Cd}, \mathrm{Co}, \mathrm{Cr}, \mathrm{Cu}, \mathrm{Mn}, \mathrm{Pb}, \mathrm{Sc}, \mathrm{Ti}, \mathrm{V}, \mathrm{Zn}$ e Zr, e mostram

Tabela 3 - Dados químicos e mineralogicos (\% em peso) para os horizontes componentes dos perfis $C$ e $D$ Table 3 - Chemical and mineralogical data (weight $\%$ ) for the three horizons of $C$ and $D$ profiles

\begin{tabular}{|c|c|c|c|c|c|}
\hline & & Perfil C & & & \\
\hline & $\mathrm{Al}_{1} \mathrm{O}_{3}$ & $\mathrm{Fe}_{2} \mathrm{O}_{3}$ & Goethita. & Caulinita & Quartzo \\
\hline $\mathrm{Hl}(\mathbf{a})$ & 6,8 & 9,6 & 10,7 & 17,2 & 72,1 \\
\hline H2(a) & 4,8 & 37,3 & 41,5 & 12,1 & 45,8 \\
\hline \multirow[t]{3}{*}{$\overline{\mathrm{H} 3}$} & 5,0 & $\overline{17,3}$ & 19,2 & 12,7 & 68,1 \\
\hline & & Perfil D & & & \\
\hline & $\mathbf{A l}_{2} \mathbf{O}_{3}$ & $\mathrm{Fe}_{2} \mathrm{O}_{3}$ & Goethita. & Caulinita & Quartzo \\
\hline $\mathrm{Hl}(0-1 \mathrm{~m})$ & 4,3 & 6,4 & 7,1 & 10,9 & 82,0 \\
\hline $\mathrm{H} 2(1-2 \mathrm{~m})$ & 4,0 & 33,0 & 36,7 & 10,1 & $\overline{53,2}$ \\
\hline $\mathrm{H} 3(2-3 \mathrm{~m})$ & 8,1 & 7,8 & 8,7 & 20,5 & 70,8 \\
\hline $\mathrm{H} 3(3-4 \mathrm{~m})$ & 8,1 & 9,4 & 10.5 & 20,5 & $\overline{69,0}$ \\
\hline $\mathrm{H} 3(4-5 \mathrm{~m})$ & 4,9 & 7,7 & 8,6 & 12,4 & 79,0 \\
\hline $\mathrm{H3}(5-6 \mathrm{~m})$ & 6,0 & 8,7 & 9,7 & 15,2 & $\overline{75,1}$ \\
\hline
\end{tabular}

geralmente em $\mathrm{Hl}$ valores mais baixos que em $\mathrm{H} 3$, seguindo portanto o comportamento do ferro. Os coeficientes de correlação Pearson, calculados para esses elementos tomados 2 a 2 e para cada um deles em relação ao Fe, é sempre positivo e elevado. São todos eles, com exceção do B, Ba e Pb, metais de transição que costumam acompanham o comportamento residual do Fe na formação das couraças (Leprun 1979). Be, Ce e Y mostram tendência de acumulação preferencial em $\mathrm{H} 2$, em apenas um dos perfis considerados. Ag, As, La e Mo estão muito próximos do limite de detecção do método analítico utilizado e, portanto, não apresentam variações significativas. $\mathrm{P}$ e $\mathrm{Sr}$ não mostram tendências regulares de comportamento.

DISCUSSÃO Os horizontes superiores dos perfis de alteração com stone Line laterítica, relacionados aos "Granitos Rondonianos" e suas encaixantes, têm sido interpretados como materiais alóctones, depositados como colúvios sobre a rocha alterada, por ocasião dos episódios de clima seco relacionados às flutuações climáticas quaternárias (Bettencourt \& Dall'Agnol 1987, Bettencourt et al. 1988). O estudo do depósito de Serra da Onça B, no distrito de Santa Bárbara, revelou que existem fortes argumentos para que uma origem autóctone de tais perfis seja considerada.

Duas ordens de argumentos podem ser evocadas. A primeira diz respeito à distribuição em área dos teores de $\mathrm{Sn}$ nos horizontes superiores do perfil de alteração.

Conforme foi visto, os mapas de isoteores de $\mathrm{Sn}$ em $\mathrm{Hl}$ e H2 mostram anomalias superponíveis, orientadas na direção geral em que se encontram os veios portadores do minério primário em $\mathrm{H} 3$, o que resulta em correlações positivas significativas entre os teores de $\mathrm{Sn}$ em Hl e H2. Esse empilhamento das concentrações de cassiterita não pode ser casual; ao contrário, deve ser derivado de uma evolução vertical essencialmente in situ. A permanência dos mesmos minerais pesados nos concetrados de bateia provenientes dos três horizontes superpostos também é um argumento em favor da hipótese de uma evolução autóctone para o perfil.

A outra linha de argumentação é baseada em dados micromorfológicos. Estes indicam que entre a alterita do horizonte saprolítico da base e o fundo matricial internodular do horizonte nodular há continuidade mineralógica e estrutural: os minerais presentes são os mesmos e estão organizados em um plasma argiloferruginoso e um esqueleto quartzoso de mesma granulometria. Além disso, em direção ao topo de $\mathrm{H} 3$, vão aparecendo, no seio da alterita, manchas avermelhadas cada vez mais endurecidas, que podem ser interpretadas como precursoras do nódulos que se encontram plenamente desenvolvidos em $\mathrm{H} 2$. Com relação à transição entre $\mathrm{H} 2$ e $\mathrm{H} 1$, essa continuidade também se faz presente, tanto no que se refere ao fundo matricial, como aos nódulos, que diminuem de tamanho e desaparecem gradativamente em direção à superfície. Assim, o que aparece como discordância numa descrição macroscópica dos perfis, e que leva à elaboração de hipóteses aloctonistas para sua génese, revela-se como produto de um desenvolvimento gradual e progressivo.

Os perfis estudados assemelham-se muito a alguns descritos na faixa intertropical africana, em áreas o embasamento pré-cambriano, estável por longos períodos e com clima úmido, como no Congo (Muller et al 1980), em Camarões (Muller \& Bocquier 1986). No Brasil, há, na própria Amazônia - nas proximidades.de Manaus -, descrição detalhada de perfis semelhantes (Lucas et al 1990). Em todos esses casos, as evidências micromorfológicas, mineralógicas e microquímicas apontam para um desenvolvimento in situ.

A hipótese proposta para a génese desses perfis, com seus níveis com stone Line laterítica subjacentes a um horizonte móvel, compreende uma fase evolutiva em clima de esta- 
Tabela 4 - Elementos traços (ppm) nos horizontes componentes dos perfis $C$ e $D$

Table 4 - Trace elements (ppm) for the three horizons of $\mathrm{C}$ and $\mathrm{D}$ profiles

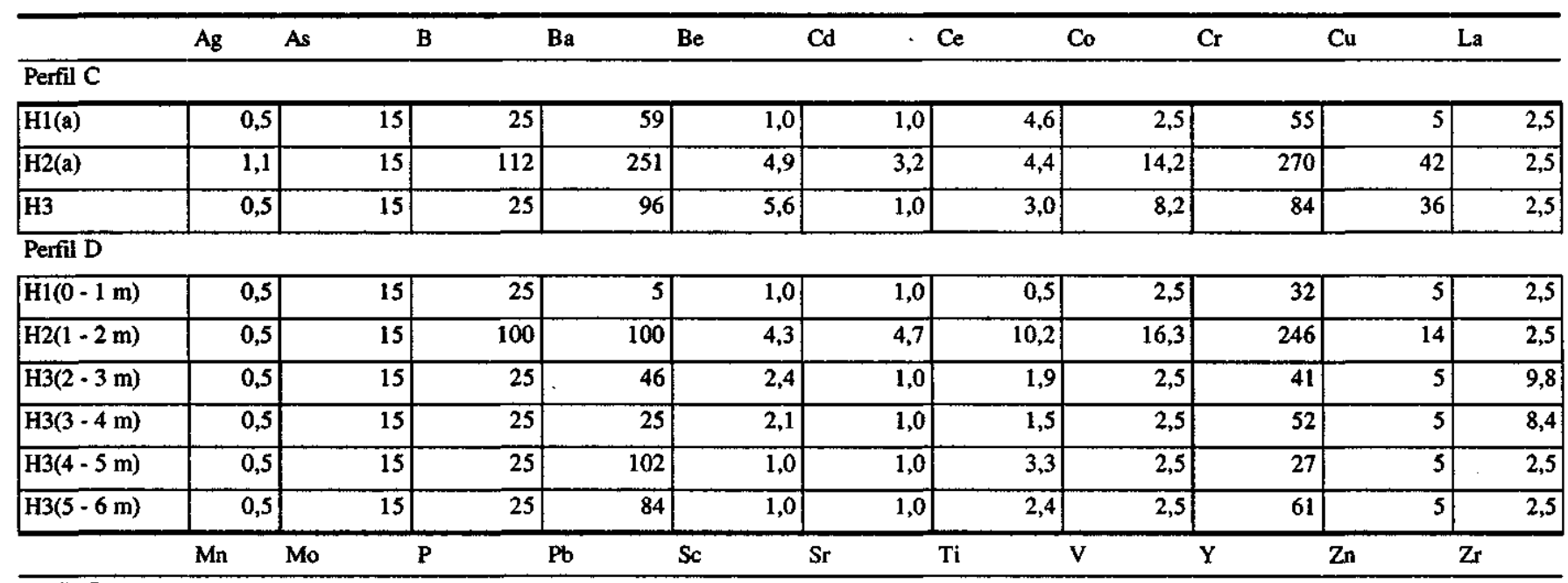

Perfil C

\begin{tabular}{|l|r|r|r|r|r|r|r|r|r|r|}
\hline H1(a) & 303 & 2,5 & 200 & 37 & 16 & 8,6 & 387 & 117 & 0,5 & 46 \\
\hline H2(a) & 998 & 2,5 & 500 & 112 & 41 & 7,4 & 1066 & 505 & 3,7 & 237 \\
\hline H3 & 405 & 2,5 & 500 & 69 & 36 & 9,5 & 825 & 317 & 1,2 & 92 \\
\hline
\end{tabular}

Perfil D

\begin{tabular}{|c|c|c|c|c|c|c|c|c|c|c|c|}
\hline $\mathrm{H} 1(0-1 \mathrm{~m})$ & 81 & 2,5 & 300 & 18 & 16 & 6,4 & 386 & 103 & 0,5 & 18 & $\overline{9}$ \\
\hline $\mathrm{H} 2(1-2 \mathrm{~m})$ & 1996 & 6,7 & 300 & 135 & $\overline{47}$ & $\overline{7,5}$ & 891 & $\overline{409}$ & 0,5 & 159 & 35 \\
\hline $\mathrm{H} 3(2-3 \mathrm{~m})$ & 198 & 2,5 & 400 & 41 & 19 & 9.8 & 483 & 110 & 1,1 & 29 & 15 \\
\hline $\mathrm{H} 3(3+4 \mathrm{~m})$ & 145 & 2,5 & 400 & 38 & 21 & 8,6 & 499 & 136 & 1,3 & 31 & 14 \\
\hline $\mathrm{H} 3(4-5 \mathrm{~m})$ & 450 & 2,5 & 300 & 33 & 19 & 7,1 & 421 & 121 & 0,5 & 23 & 12 \\
\hline$H 3(5-6 m)$ & 386 & 5,1 & 200 & 30 & 17 & 8,2 & 314 & 120 & 0,5 & 29 & 18 \\
\hline
\end{tabular}

coes contrastadas, quando teria se formado uma couraça ferruginosa, seguida de uma fase de degradação dessa couraça, com efeito de mudança climática em direção a condições mais úmidas (Nahon 1986).

As couraças desenvolvem-se através de movimentos verticais para baixo do $\mathrm{Fe}$ e de minerais resistentes a alteração intempérica, acompanhando o abaixamento do relevo (Roquim et al. 1990). Essa acumulação absoluta de Fe provoca a desestabilização, seguida de dissolução, da caulinita e do quartzo, o que intensifica a acumulação do Fe, levando à formação de couraças maciças, autóctones e litodependentes.

A degradação da couraça inicia-se pela brechação e nodulação, através de processos de deferruginização e redistribuição do $\mathrm{Fe}$, dando origem a uma fácies nodular pseudoconglomerática. Com o prosseguimento da deferruginização, ocorre digestão química dos nódulos, o que engendra a acumulação residual de caulinita e principalmente de quartzo (Bocquier et al. 1984). O resultado desse processo é um perfil de alteração que contém um horizonte com stone Line laterítica, representando os restos da antiga couraça, capeado por um horizonte móvel, formado pelos materiais residuais produzidos pela sua degradação. A evolução do perfil é, portanto, essencialmente vertical, embora comporte uma certa dispersão lateral dos materiais, que vai se tornando mais acentuada em direção aos horizontes superiores.

Na região de Serra da Onça B, o encouraçamento se teria dado sob um clima mais seco que o atual, que teria aí prevalecido até pelo menos o Eoceno, há 50 milhões de anos atrás (Tardy et al. 1990 e 1991). Na couraça, junto com o Fe, concetraram-se os elementos traços de comportamento se- melhante, além da cassiterita. Com o deslocamento do continente sul-americano em direção ao norte durante o Terciário (Tardy et al 1990 e 1991), o clima de Rondônia foi se tornando cada vez mais úmido. Em consequência, a couraça entrou em desequilíbrio e começou a degradar-se. Esse processo gerou nódulos, no seio dos quais houve dissolução de quartzo e acumulação de Fe. Os nódulos vão aparecer como que cimentados por uma matriz enriquecida em quartzo e cassiterita, o que dá à couraça aspecto pseudo-conglomerático. Os restos de couraça nodular encontrados no terço inferior das encostas testemunham essa etapa do processo.

$\mathrm{O}$ avanço na degradação da couraça levou à destruição dos nódulos e à reorganização do esqueleto quartzoso e do plasma caulinítico da matriz. Esse material vai constituir o essencial do horizonte móvel (H1) que recobre o horizonte portador dos nódulos ainda não-digeridos (H2). Um movimento para baixo dos grãos mais grossos, a lixiviação dos finos por flutuação do lençol Jreático e a atividade dos cupins, levando os finos para cima, são processos que também têm sido evocados (Lacomte 1988, por exemplo) como atuantes na diferenciação desse tipo de perfil.

Nahon et al (1989) sugeriram que o destino das couraças na região amazônica é sua transformação em latossolos, como consequência da transição para condições climáticas mais úmidas, a partir do Terciário. Nessa perspectiva, os perfis com horizonte nodular de Serra da Onça B representariam uma etapa intermediária na substituição de um sistema pedológico por outro.

CONSIDERAÇÕES FINAIS Do ponto de vista metalogenético, o depósito, caracterizado pela concentração má- 
xima de cassiterita no horizonte $\mathrm{H} 2$, resulta da acumulação desse mineral a partir da coluna de rocha previamente sobreposta, transformada em couraça ferruginosa. O movimento para baixo da cassiterita, durante a formação da couraça, foi mais intenso para os grãos maiores, o que explica o aumento de sua granulometria em H2. A degradação da couraça, com consequente diferenciação do perfil, intensificou a concentração de cassiterita em $\mathrm{H} 2$, e gerou acima um horizonte essencialmente quartzoso $(\mathrm{Hl})$, onde os teores de cassiterita encontram-se diluídos cerca de 10 vezes em relação ao horizonte subjacente. Dentro desse esquema interpretativo, a idade da mineralização seria terciária, mais antiga, portanto, que a comumente admitida a partir das hipóteses aloctonistas.

Com relação às aplicações práticas, pode-se dizer que, em perfis de alteração derivados de degradação de couraças lateríticas, o horizonte móvel do topo é especialmente adequado para a prospecção geoquímica. Devido à evolução essencialmente vertical do perfil, com pequena dispersão lateral, provocada pelo colapso e consequente redução de volume de seus níveis superiores, estes vão refletir o substrato e ampliar o alcance das anomalias, permitindo que elas sejam mais facilmente detectadas. Esse efeito foi descrito, por exemplo, por Lecomte \& Colin (1989), em terrenos lateríticos do Gabão, onde anomalias de ouro apresentam em seção vertical forma de cogumelo enraizado na mineralização primária. Neste caso, entretanto, além de resultado do colapso, a dispersão do ouro tem uma componente química, ligada à dissolução das partículas. Em Serra da Onça B, o maior espalhamento dos teores anómalos de $\mathrm{Sn}$ em $\mathrm{Hl}$, verificado durante a prospecção geoquímica, pode ser atribuído apenas ao efeito do colapso, dada a enorme resistência à alteração da cassiterita.

Finalmente, deve-se acrescentar que, em vista da complexidade dos fenómenos pedológicos, tanto atuais como pretéritos. É preciso levar em conta dificuldades eventuais na interpretação de certos perfis de alteração, nos quais a possibilidade de aportes alóctones, com consequente prejuízo para a correlação substrato-cobertura, não deve ser descartada.

Agradecimentos Os autores agradecem à Companhia Estanífera do Brasil, que liberou a informação referente à fase de pesquisa mineral da jazida, além de permitir o trabalho de campo e a utilização dos laboratórios da empresa para obtenção de dados analíticos. São também gratos ao geólogo Mauro Fumio Yamamoto, pelas análises químicas. O Prof. J.S. Bettencourt discutiu com os autores as principais ideias contidas neste trabalho, e através de sua judiciosa crítica a versão final foi significativamente melhorada. Os comentários construtivos de um revisor anônimo também constituíram contribuição importante na elaboração definitiva do texto.

\section{REFERÊNCIAS BIBLIOGRÁFICAS}

ALMEIDA, F.F.M; HASUI, Y.; BRITO NEVES, B.B.; FUCK, R.A. 1981. Brazilian structural provinces: and introduction. Earth Sci. Rev., 17:1-29

BETTENCOURT, J.S. \& DAL'AGNOL, R. (coord) 1987. The Rondonian tin bearing anorogenic granites and associated mineralization: In: SYMP. GRANITES AND ASSOC. MIN. Salvador, 1987. Excursion Guide... Salvador, ISGAM. p. 49-87.

BETTENCOURT, J.S.; MUZZOLON, R.; PAVOLLA, B.L.; DALUIGNA, L.G.; PINHO, O.G. 1988. Depósitos estaníferos secundários da região central de Rondônia. In: SCHOBBENHAUS, C. \& COELHO, C.E.S. coord. Depósitos Minerais do Brasil. Rio de Janeiro, DNPM. v. III, p. 213-241.

BOCQUIER, G.; MULLER, J.P.; BOULANGÉ, B. 1984. Les latérites: connaissances et perspectives actuelles sur les mecanismes de leur differenciation. In: LIVRE JUBILAIRE CINQUANTENAIRE AFES. Paris. p. 123-138.

CARVALHO, R.T. 1988. Depósitos de cassiterita de Santa Bárbara, Jacundá e Alto Candeias, Rondônia. In: SCHOBBENHAUS, C.; COELHO, C.E.S. coord. Depósitos Minerais do Brasil. Rio de Janeiro, DNPM. v. Hl, p. 243-253.

EDOU-MINKO, A. 1988. Pétrologie et Géochimie des Latérites à "StoneLines" du Gite d'or d'Ovala. Applications à la Prospection en Zone Equatoriale Humide (Gabon). France. 186 p. (Thése Doct., Universite Poitiers).

LEAL, J.W.L.; SILVA, B.H.; SANTOS, D.B.; TEIXEIRA, W.; LIMA, M.I.C.; FERNANDES, C.A.C.; PINTO, A.C. 1978. Geologia. In: MME - PROJETO RADAMBRASIL. Folha SC-20 Porto Velho. Rio de Janeiro, DNPM. p. 1-161. (Levantamento de Recursos Naturais 16).

LECOMTE, P. 1988. Stone line profiles: importance in geochemical exploration. J. Geoch. Expl., 30:35-61.

LECOMTE, P.; COLIN, F. 1989. Gold dispersion in a tropical rainforest weathering profile at Dondo Mobi, Gabon. J. Geoch. Expl., 34:285301.

LEPRUN, J.C. 1979. Les cuirrasses ferrugineuses des pays cristallins de 1'Afrique occidentale sèche. Genése, transformation, dégradation. Sci. Géol. Mém., Strasbourg, v. 58, 224 p.

LUCAS, Y.; COULET, R.; CHAUVEL, A. 1990. Modalité de Ia formation in situ de stone lines en zone équatoriale. Example d'une couverture ferralitique d'Amazonie au Brésil. C. R. Acad. Sci., Sér. 2, 311:713-718.
MULLER, D.; BOCQUIER, G.; NAHON, D.; PAQUET, H. 1980. Analyse des differenciations minéralogiques et structurales d'un sol ferralitique à horizons nodulaires du Congo. Cah. ORSTOM, Sér. Pedologie, 18(2):87-109.

MULLER, J.P.; BOCQUIER, G. 1986. Dissolution of kaolinites and accumulation of iron oxides in lateritic-ferruginous nodules: mineralógical and microstructural transformation. Geoderma, 137:113-136.

NAHON, D. 1986. Evolution of iron crust in tropical landscape. In: COLMAN, S.M.; DETHIER, D.P. eds. Rates of Chemical Weathering of Rocks and Minerais. New York, Academie Press. p. 169-191.

NAHON, D.; MELFI, A.J.; CONTE, C.N. 1989. Présence d'un vieux systeème de cuirrasses ferrugineuses latéritiques en Amazonie du Sud. La transformation in situ en latossols sous la forêt équatoriale acturelle. C. R. Acad. Sci, Ser. 2, 308:755-760.

ROQUIN, C.; PAQUET, H.; PREYSSINET, P.; BOEGLIN, J.L.; TARDY, D.Y. 1990. Lithodependence and homogenisation of mineralogical and chemical composition of ferricretes. Chem. Geol., 84(1/4):124-127.

SCHOBBENHAUS, C.; CAMPOS, D.A.; DERZE, G.R.; ASMUS, H.E. (coord.) 1981. Mapa Geológico do Brasil e da Area Oceânica Adjacente Incluindo Depósitos Minerais. Brasília, MME-DMPM.

TARDY, Y; KOBILSEK, B.; ROQUIN, C.; PAQUET, H. 1990. Influence of periatlantic climates and paleoclimates on the distribution and mineralogical composition of bauxites and ferricretes. Chem. Geol., 84(1/4):129-182.

TARDY, Y; KOBILSEK, B. PAQUET, H 1991. Mineralogical composition and geographical distribution pf African and Brazilian periatlantic latérites. The influence of continental drift and tropical paleoclimates during the past $150 \mathrm{~m} . \mathrm{y}$. and implication for india and Austrália. J. Afr. Earth Sci., 12(1/2):283-295.

VALENTE, J.C.P. 1991. Concentração Supergênica de Cassiterita em uma Stone Line Laterítica na Jazida de Serra da Onça B, Porto Velho - RO. Rio de Janeiro, 100 p. (Dissertação de Mestrado, IQ-UFF).

MANUSCRITO A760 Recebido em 30 de abril de 1993 Recebido do autor em 20 de julho de 1993 Revisão aceita em 20 de julho de 1993 